\title{
KNOWLEDGE AND PERCEPTIONS OF VITAMIN D DEFICIENCY AMONG THE UNITED ARAB EMIRATES POPULATION
}

\begin{abstract}
OSAMA MOHAMED IBRAHIM ${ }^{1,2 *}$, NOOR KIFAH AL-TAMEEMI ${ }^{1}$, DALIA DAWOUD ${ }^{2,3}$
${ }^{1}$ Department of Pharmacy Practice and Pharmacotherapeutics, College of Pharmacy, University of Sharjah, Sharjah, United Arab Emirates. ${ }^{2}$ Department of Clinical Pharmacy, Faculty of Pharmacy, Cairo University, Egypt. ${ }^{3}$ Department of Clinical and Pharmaceutical Sciences School of Life and Medical Sciences, University of Hertfordshire, United Kingdom. Email: oibrahim@sharjah.ac.ae
\end{abstract}

Received: 08 May 2019, Revised and Accepted: 24 June 2019

ABSTRACT

Objectives: The purpose of this study is to assess the Vitamin D deficiency awareness and perceptions between the United Arab Emirates (UAE) population.

Methods: A cross-sectional study was done among the population of two emirates at the UAE: Abu Dhabi and Sharjah.

Results: Overall, 434 participants completed the survey. Majority of people were aware of phenomenon of Vitamin D deficiency, but only $21.4 \%$ of them knew that sunlight is considered the main source of Vitamin D. Moreover, less than half of participants check their Vitamin D blood level regularly and around $55 \%$ of them follow-up with their physicians after completing the treatment. High proportion of participant females spend $<1$ h outdoors (60\%) and use sunscreen daily (55\%) that cause higher prevalence of Vitamin D deficiency among females than males (83\% vs. 42\%).

Conclusion: This research gives some insights regarding the UAE population's awareness and perceptions of Vitamin D insufficiency. Decreased awareness of sunlight exposure as a major source of Vitamin D, in addition to lifestyle, contributed to Vitamin D deficiency problem among the UAE population, in general, and in females, in particular.

Keywords: Vitamin D deficiency, Insufficiency, Awareness, Perceptions, Prevalence, United Arab Emirates.

(C) 2019 The Authors. Published by Innovare Academic Sciences Pvt Ltd. This is an open access article under the CC BY license (http://creativecommons. org/licenses/by/4. 0/) DOI: http://dx.doi.org/10.22159/ajpcr.2019.v12i8.33988

\section{INTRODUCTION}

Vitamin D insufficiency and deficiency become major health problem worldwide, particularly in the Middle East and North Africa. During the past decade, many researchers conducted that there showed high rate of Vitamin D deficiency although these areas are sunny in most time of the year. According to studies, more than $90 \%$ of people living in the United Arab Emirates (UAE) are suffering from Vitamin D deficiency in 2017. This percentage is expected to increase in the coming years [1-3].

Vitamin D, 25-hydroxyvitamin D (25(OH)D), is a vital fat-soluble vitamin that regulates calcium homeostasis and is essential for bone and muscle health in people of all ages. It naturally presents in some foods as well as certain dietary supplements and is produced endogenously when sunlight strikes the skin which stimulates Vitamin D synthesis. Serum concentration of $25(\mathrm{OH}) \mathrm{D}$ is the best indicator of Vitamin D status in humans, with values of $<30 \mathrm{nmol} / \mathrm{L}(\mathrm{nmol} / \mathrm{L}=0.4 \mathrm{ng} / \mathrm{mL})$ considered to be inadequate for the general health and well-being of adults. The amount of Vitamin D active metabolites produced depends mainly on the kidney function and the degree of sunlight exposure [4-6]

A plethora of epidemiological and observational studies has demonstrated the correlation between Vitamin D and overall human health [7-9]. Studies suggest that sufficient Vitamin D serum of more than $30 \mathrm{nmol} / \mathrm{L}$ is implicated in preventing cardiovascular disease. An adequate Vitamin D serum level has also been reported to enhance the immune system, prevent cancer, and limit its progression. In addition, Vitamin D plays a role in the prevention and control of diabetes [10-16].

Skin exposure to sunlight is considered as the major source of Vitamin D in human bodies, where the amount produced from sunlight is equal to ingesting an amount of dietary Vitamin D ranging from 10,000 to 25,000 IU. In addition, the form of Vitamin D produced after being exposed to the sun will last in the blood for twice the time compared to the form ingested from the diet or supplements. Few types of food are known to contain Vitamin D2 or D3 in good amount such as cod liver oil, salmon, sardines, tuna, and egg yolk $[15,16]$.

The major risk factors for Vitamin D deficiency include insufficient sunlight exposure, especially for people with dark skin color, use of sunscreens with sun protection factor (SPF) of 15. Elderly, obese, and institutionalized people are more at risk from Vitamin D deficiency. This also includes vegetarian people or those who are not eating food that contains Vitamin $\mathrm{D}$ and infants who are being exclusively breastfed, especially if they are older than 6 months, as the breast milk does not have enough Vitamin D content that matches their need for it at their age $[17,18]$.

This study was done to identify the UAE population's knowledge and practice toward Vitamin D deficiency because only a few studies were conducted in the Middle East, especially in the UAE.

\section{METHODS}

Study design, settings, and questionnaire development

This is a cross-sectional descriptive study which was conducted in two major cities in the UAE: Abu Dhabi and Sharjah. After reviewing many studies about Vitamin D deficiency [19-24], the questionnaire was developed to cover all the aims of the study. Then, the questionnaire was validated by many members from the faculty of pharmacy at University of Sharjah and it was examined for content appropriateness. Finally, the final version of the questionnaire was written, and some modifications were done according to faculty's comments.

The survey contained three sections and each section involved several questions. The first section of the survey was compromised of the sociodemographic profile of the participants. Moreover, the second 
section included general questions regarding Vitamin D deficiency to examine UAE population's knowledge of Vitamin D. In addition, the third section comprised questions about the perceptions and practice of the population toward Vitamin D deficiency.

\section{Study participants}

Using a convenient sampling method, a total of 500 individuals from different communities in the Emirates of Abu Dhabi and Sharjah participated in the survey.

Participants were informed about the goals and content of the questionnaire before answering it. Arabic and English speakers aged above 18 years old were included in the study, whereas population aged under 18 years old were excluded from the study.

\section{Ethical approval}

Approval for distributing the questionnaires was obtained from University of Sharjah Research Ethics Committee.

\section{Data analysis}

Descriptive analysis was conducted to determine the knowledge and perceptions of Vitamin D deficiency among the UAE population. All data were entered and analyzed using the SPSS Version 20. All results are presented as percentage (\%).

\section{RESULTS}

\section{Demographic information}

A total of 500 surveys were distributed and 434 questionnaires were returned with response rate of $86.8 \%$.

Table 1 shows the frequency of participants according to sociodemographic characteristics. Most of participants were female ( $\mathrm{n}=267,61.5 \%)$. Moreover, majority of responders were from Abu Dhabi $(n=224,51.6 \%)$ and a smaller number of people were from Sharjah $(n=210,48.4 \%)$.

\section{Participants' knowledge of Vitamin D}

High proportion of responders was aware regarding phenomenon of Vitamin D deficiency ( $\mathrm{n}=388,89 \%)$ and only $21.4 \%$ of them knew that the percentage of Vitamin D coming from the sun is equal to $90 \%$.

Fig. 1 shows people answers regarding the best food source of Vitamin D. Majority of people chose salmon ( $\mathrm{n}=241,55.5 \%)$, which is considered as the correct answer. However, $31.8 \%$ of participants chose milk and $8.1 \%$ of them considered chicken to be the best food source of Vitamin D as well as 20 responders chose meat.

\section{Perceptions of the UAE population toward Vitamin D deficiency}

Fig. 2 displays the differences in people practice regarding insufficiency of Vitamin D based on gender variation. Most of females (60\%) agreed that they spend regularly $<1 \mathrm{~h}$ outdoors during day time. However, high percentage of males (47\%) reported that they spend more than $1 \mathrm{~h}$ outdoors daily. Moreover, only $7 \%$ of male participants use sunscreen every day while more than half of female responders put sunscreen daily (55\%). In addition, although $87 \%$ of males consume diet rich in Vitamin D and $74 \%$ of females do that, but low percentage of males (36\%) and females (42\%) check their Vitamin D blood level regularly. Furthermore, out of those who always check their Vitamin D blood level, Fig. 3, $42 \%$ of males and $83 \%$ of females reported that they had low levels of Vitamin D. In addition, many males (51\%) and females (57\%) try to follow up with their physicians after completing their treatment regimen as well as most of males (74\%) and females (75\%) reported that their symptoms improved after taking treatments and all males $(100 \%)$ and majority of females had an increased level of Vitamin D after taking the treatments.

\section{DISCUSSION}

The result of this study showed an increased level of awareness of the UAE population about Vitamin D deficiency phenomenon and the best
Table 1: Sociodemographic data

\begin{tabular}{ll}
\hline Characteristics & n (\%) \\
\hline Total & $434(100.0)$ \\
Gender & \\
$\quad$ Male & $167(38.5)$ \\
$\quad$ Female & $267(61.5)$ \\
Emirate & \\
$\quad$ Abu Dhabi & $224(51.6)$ \\
Sharjah & $210(48.4)$ \\
\hline
\end{tabular}

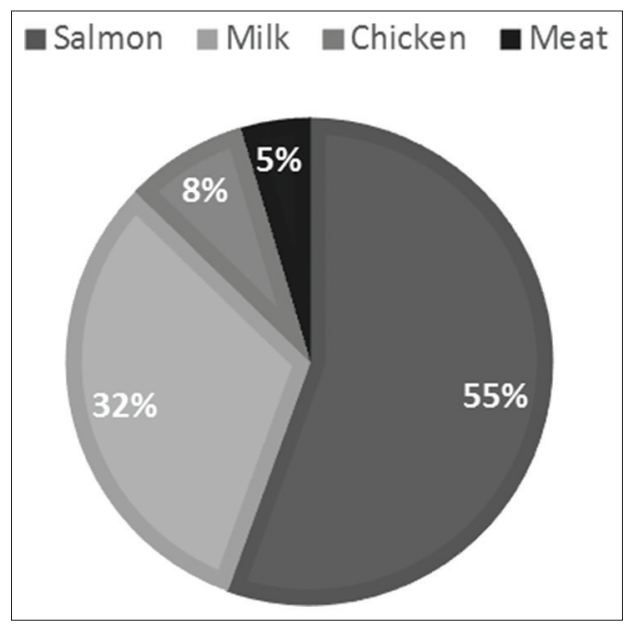

Fig. 1: Best food source of Vitamin D

food sources of Vitamin D. Similarly, in the United Kingdom, a crosssectional study showed that

$72 \%$ of participants knew general information about Vitamin D, but around $54 \%$ of them did not know the symptoms of Vitamin D insufficiency [25]. Moreover, a survey conducted in Jeddah, Saudi Arabia, reported that more than half of the responders understood Vitamin D benefits, but majority had poor awareness regarding food sources that are rich with Vitamin D [26]

Vitamin D is found naturally in very few food sources. This includes salmon, liver, and egg yolks. Nowadays, several countries produce foods fortified with Vitamin D, such as cereals, milk, juices, and many dairy products that usually contain 100 IU per portion $[27,28]$.

On the other hand, this research reported that people significantly underestimated the importance of sunlight exposure as a major source of Vitamin D. In fact, the sun provides $90 \%$ of the daily requirements of Vitamin D [23-25,29]; however, most of the population (78.6\%) did not answer correctly. This result explains why people do not consider exposing themselves to sunlight daily as an important issue. According to this research, $60 \%$ of females and $53 \%$ of males spend $<1 \mathrm{~h}$ daily outdoors. This could be a major cause of their Vitamin D deficiency. Based on recent review study about Vitamin D deficiency and insufficiency in the Middle East and Africa, three factors were considered as major etiological factors associated with Vitamin D deficiency at UAE; body mass index, fast-food diet, and inadequate sun exposure [30].

In addition, according to this study, high proportion of females (55\%) was using sunscreen every day, while males showed a very limited usage of sunscreen (7\%); this could be one of the possible explanations why females in this study showed a higher percentage of deficiency than males. The previous studies have been reported that using sunscreen reduces the absorption of ultraviolet B radiation. Moreover, sunscreen with SPF of 15 or more reduces Vitamin D synthesis in the skin by 99\% [31]. 


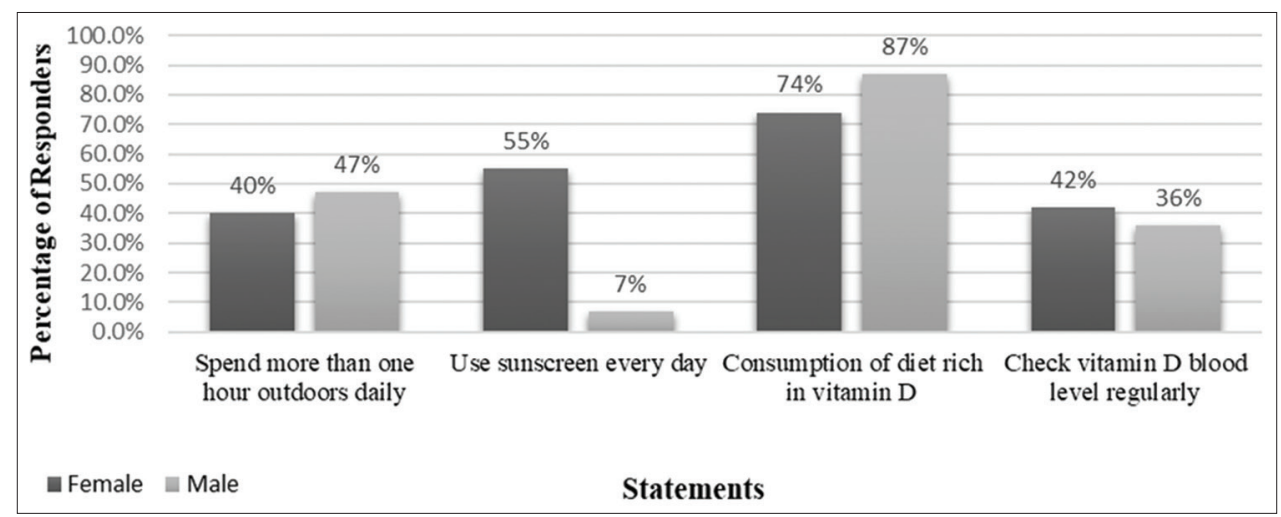

Fig. 2: United Arab Emirates population's perceptions regarding insufficiency of Vitamin D

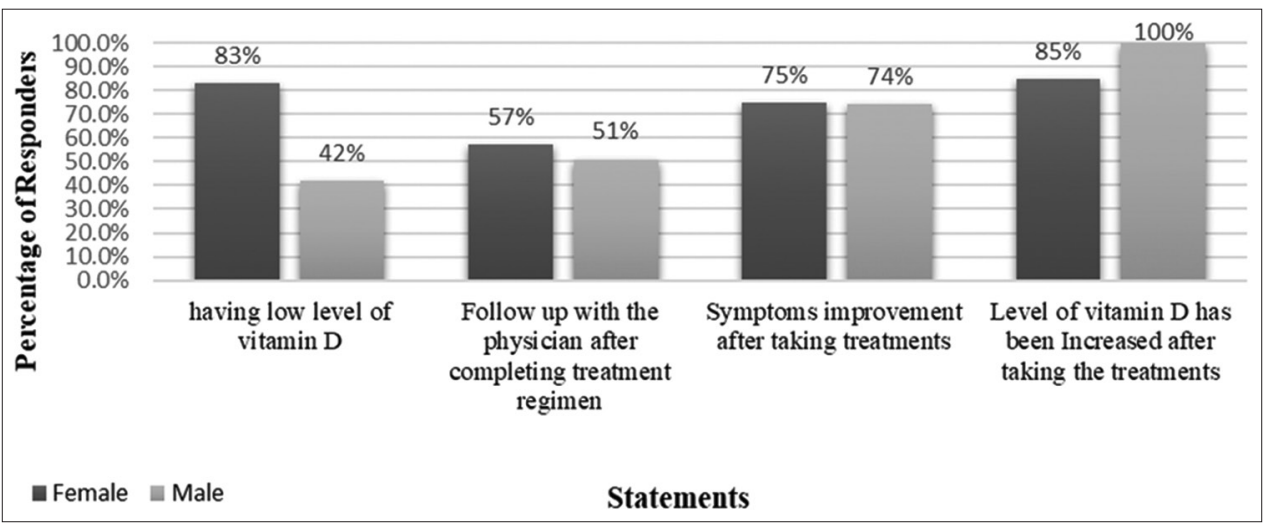

Fig. 3: Perceptions toward Vitamin D deficiency treatment among the United Arab Emirates population

Regarding daily consumption of a Vitamin D-rich diet, it was obvious that the percentage of females consuming this type of diet is less than that of males; this result, besides the previous results of using sunscreen and the time spent outdoors, might explain the high prevalence of Vitamin D deficiency in female subjects as compared to the male subjects [32].

This survey showed that less than half of population check their Vitamin D blood level regularly and around half of them follow-up with their physicians after completing their treatment regimen. This because of the lack of awareness regarding the importance of Vitamin D deficiency treatment. Vitamin D is necessary in the memantine of teeth and bone and strength the immunity. Inadequate level of Vitamin D can lead to many health problems such as loss of bone density, which can cause osteoporosis and fractures in adults and rickets in children [22].

Regarding the treatment aspects covered in this study, majority of participants showed an improvement of symptoms after receiving the treatment, regardless of gender.

\section{Limitations}

This study used the convenience sampling technique and conducted only at two cities in the UAE, out of seven, so the results of this research cannot extrapolate to predict the knowledge and attitudes of whole UAE population.

\section{CONCLUSION}

This study gives some insights regarding the UAE population's knowledge and perceptions of Vitamin D deficiency. Decreased awareness of sunlight exposure as a major source of Vitamin D, in addition to lifestyle, contributed to the deficiency problem in the UAE population and this emphasizes the importance of improving population awareness of the consequences of Vitamin D deficiency and strategies to avoid it.

\section{ACKNOWLEDGMENT}

The authors gratefully acknowledge Ms. Aseel Nassar for her valuable help and support.

\section{AUTHORS' CONTRIBUTIONS}

All authors researched data and wrote the manuscript. All authors read and approved the final manuscript.

\section{CONFLICTS OF INTEREST}

The authors declare that they have no conflicts of interest in this work.

\section{REFERENCES}

1. Holick MF, Chen TC. Vitamin D deficiency: A worldwide problem with health consequences. Am J Clin Nutr 2008;87:1080S-6.

2. Alshamsan FM, Bin-Abbas BS. Knowledge, awareness, attitudes and sources of vitamin D deficiency and sufficiency in Saudi children. Saudi Med J 2016;37:579-83.

3. $90 \%$ of UAE Population Vitamin D Deficient Says DHA Official. Gulfnews.com. Available from: https://gulfnews.com/going-out/ society/90-of-uae-population-vitamin-d-deficient-says-dhaofficial-1.2113556. [Last accessed on 2019 Mar 30].

4. Vitamin D Fact Sheet for Health Professionals. National Institute of Health. Available from: https://ods.od.nih.gov/factsheets/VitaminDHealthProfessional/. [Last accessed on 2019 Mar 1].

5. Del Valle HB, Yaktine AL, Taylor CL, Ross AC, editors. Dietary Reference Intakes for Calcium and Vitamin D. $1^{\text {st }}$ ed. Washington: The National Academies Press; 2011.

6. Agens JE, Galasko GT, Purandare AV, Lin J. Awareness of vitamin D deficiency states and recommended supplementation doses: Survey of faculty and staff at a medical school. e-SPEN J 2012;7:e215-8.

7. Holick MF. Vitamin D: Importance in the prevention of cancers, type 1 diabetes, heart disease, and osteoporosis. Am J Clin Nutr 2004;79:362-71.

8. Hossein-nezhad A, Holick MF. Vitamin D for health: A global perspective. Mayo Clin Proc 2013;88:720-55. 
9. Holick MF. Sunlight and vitamin D for bone health and prevention of autoimmune diseases, cancers, and cardiovascular disease. Am J Clin Nutr 2004;80:1678S-88.

10. Mozos I, Marginean O. Links between vitamin D deficiency and cardiovascular diseases. Bio Med Res Int 2015;2015:109275.

11. Chirumbolo A. Vitamin D3 in cancer prevention and therapy: The nutritional issue. Horm Mol Biol Clin Investig 2015;23:71-8.

12. Nikooyeh B, Neyestani TR, Farvid M, Alavi-Majd H, Houshiarrad A, Kalayi A, et al. Daily consumption of vitamin D- or vitamin D + calcium-fortified yogurt drink improved glycemic control in patients with type 2 diabetes: a randomized clinical trial. Am J Clin Nutr 2011;93:764-71.

13. Menon RK, Rickard AP, Mannan N, Timms PM, Sharp SJ, Martineau A, et al. The effects of vitamin D 2 or D 3 supplementation on glycaemic control and related metabolic parameters in people at risk of type 2 diabetes: Protocol of a randomised double-blind placebo-controlled trial. BMC Public Health 2013;13:999.

14. De Courten B, Mousa A, Naderpoor N, Teede H, de Courten MP, Scragg R. Vitamin D supplementation for the prevention of type 2 diabetes in overweight adults: Study protocol for a randomized controlled trial. Trials 2015;16:335.

15. Wolpowitz D, Gilchrest BA. The vitamin D questions: How much do you need and how should you get it? J Am Acad Dermatol 2006;54:301-17.

16. Holick MF, Binkley NC, Bischoff-Ferrari HA, Gordon CM, Hanley DA, Heaney RP, et al. Evaluation, treatment, and prevention of Vitamin d deficiency: An endocrine society clinical practice guideline. J Clin Endocrinol Metab 2011;96:1911-30.

17. Holick MF. Vitamin D deficiency. N Engl J Med 2007;357:266-81.

18. Pearce SH, Cheetham TD. Diagnosis and management of Vitamin D deficiency. BMJ 2010;340:b5664.

19. Lu Z, Chen TC, Zhang A, Persons KS, Kohn N, Berkowitz R, et al. An evaluation of the VSitamin D3 content in fish: Is the vitamin D content adequate to satisfy the dietary requirement for vitamin D? J Steroid Biochem Mol Biol 2007;103:642-4.

20. Food Sources of Vitamin D. Dietitians of Canada. Available from: http:// www.unlockfood.ca/en/Articles/Vitamins-and-Minerals/What-youneed-to-know-about-Vitamin-D.aspx. [Last accessed on 2019 May 1].

21. Calcium and Vitamin D: Top Foods to Prevent Osteoporosis. WebMD. Available from: https://www.webmd.com/food-recipes/guide/calcium- vitamin-d-foods. [Last accessed on 2019 May 1].

22. Gagnon C, Lu ZX, Magliano DJ, Dunstan DW, Shaw JE, Zimmet PZ, et al. Serum 25-hydroxyvitamin $\mathrm{D}$, calcium intake, and risk of type 2 diabetes after 5 years: Results from a national, population-based prospective study (the Australian Diabetes, Obesity and Lifestyle study). Diabetes Care 2011;34:1133-8.

23. Sunlight Exposure and Vitamin D Advice. NHS. UK. Available from: http://www.nhs.uk/news/2010/12December/Pages/sunlight-exposureand-vitamin-d-advice.aspx. [Last accessed on 2019 April 25].

24. Holick MF. McCollum Award Lecture, 1994: Vitamin D new horizons for the $21^{\text {st }}$ century. Am J Clin Nutr 1994;60:619-49.

25. Alemu E, Varnam R. Awareness of vitamin D deficiency among at-risk patients. BMC Res Notes 2012;5:17.

26. Alamoudi LH, Almuteeri RZ, Al-Otaibi ME, Alshaer DA, Fatani SK, Alghamdi MM, et al. Awareness of vitamin D Deficiency among the general population in Jeddah, Saudi Arabia. J Nutr Metab 2019;2019:4138187.

27. Lamberg-Allardt C. Vitamin D in foods and as supplements. Prog Biophys Mol Biol 2006;92:33-8.

28. Gupta A. Fortification of foods with vitamin D in India. Nutrients 2014;6:3601-23.

29. Haddad JG, Matsuoka LY, Hollis BW, Hu YZ, Wortsman J. Human plasma transport of vitamin D after its endogenous synthesis. J Clin Invest 1993;91:2552-5.

30. Green RJ, Samy G, Miqdady MS, El-Hodhod M, Akinyinka OO, Saleh G, et al. Vitamin D deficiency and insufficiency in Africa and the Middle East, despite year-round sunny days. S Afr Med J 2015;105:603-5.

31. How Much Vitamin D Do You Get from the Sun?. Available from: http://health.howstuffworks.com/wellness/food-nutrition/vitaminsupplements/how-much-vitamin-d-from-sun2.htm. [Last accessed on 2019 Apr 28].

32. Lim JS, Kim KM, Rhee Y, Lim SK. Gender-Dependent Skeletal Effects of Vitamin D Deficiency in a Younger Generation. J Clin Endocrinol Metab 2012;97:1995-2004. 